\title{
Turismo Cultural e Museus: o papel das tecnologias da informação
}

\author{
Turismo Cultural y Museos: el papel de las tecnologías de la información \\ Cultural Tourism and Museums: the role of information technology
}

\author{
Alice Leoti ${ }^{1}$ \\ Eugenio Manoel Prego ${ }^{2}$ \\ Lucimari Acosta Pereira ${ }^{3}$
}

\begin{abstract}
Resumo
O turismo se caracteriza pela prática do deslocamento, com finalidade de lazer, negócios dentre outras (OMT, 2001). Neste contexto emergem as viagens de lazer motivadas pelo segmento de turismo cultural que abrange diversas atividades de imersão cultural no destino (BRASIL, 2010). Os museus, como um dos elementos do turismo cultural, são conhecidos de como lugares onde se guardam e exibem coleções que refletem algum aspecto da existência humana ou seu entorno. Com o avanço da sociedade e das tecnologias o fato de mostrar a informação e como apresentá-la se tornou cada vez mais relevante. Destarte, o visitante não quer mais ser um espectador passivo, pois num mundo de conteúdo on-demand (sob demanda) em que ele escolhe o que quer ver, como e quando, a forma com que esta informação é extremamente relevante para capturar sua atenção. Nesse sentindo, o objetivo deste estudo é fazer uma abordagem conceitual sobre uso de tecnologias digitais empregadas para uma melhor dinâmica em museus e seu papel educativo. Para tanto utiliza-se uma metodologia de abordagem qualitativa exploratória, com técnica de levantamento bibliográfico em livros e artigos científicos encontrados em bases de dados, sobre a referida temática de estudo. Como resultados de estudo, elenca-se que a literatura mostra a importância do uso e do avanço da tecnologia da informação para área do turismo e para própria preservação de museus.
\end{abstract}

Palavras-Chave: Museus; Tecnologia da Informação; Turismo.

\section{Resumen}

El turismo se caracteriza por la práctica del desplazamiento, con fines de ocio, negocios entre otras (OMT, 2001). En este contexto emergen los viajes de ocio motivados por el segmento de turismo cultural que abarca diversas actividades de inmersión cultural en el destino (BRASIL, 2010). Los museos, como uno de los elementos del turismo cultural, son conocidos como lugares donde se guardan y exhiben colecciones que reflejan algún aspecto de la existencia humana o su entorno. Con el avance de la sociedad y de las tecnologías el hecho de mostrar la información y cómo presentarla se ha vuelto cada vez más relevante. Por lo tanto, el visitante ya no quiere ser un espectador pasivo, pues en un mundo de contenido on-demand (bajo demanda) en que él escoge lo que quiere ver, cómo y cuándo, la forma en que esta información es extremadamente relevante para capturar su atención . En este sentido, el objetivo de este estudio es hacer un enfoque conceptual sobre el uso de tecnologías digitales empleadas para una mejor dinámica en museos y su papel educativo. Para ello se utiliza una metodología de abordaje cualitativo exploratorio, con técnica de levantamiento bibliográfico en libros y artículos científicos encontrados en bases de datos, sobre la referida temática de estudio. Como resultados de estudio, se

\footnotetext{
1 Mestra em Memória Social e Patrimônio Cultural; UNIPAMPA; Jaguarão, Rio Grande do Sul, Brasil; aliceleoti@hotmail.com

2 Acadêmico do Curso Superior de Tecnologia em Gestão de Turismo da Universidade Federal do Pampa; UNIPAMPA; Jaguarão, Rio Grande do Sul, Brasil; eugenio.prego@gmail.com

3 Mestra em Turismo e Hotelaria; FURG; Santa Vitória do Palmar, Rio Grande do Sul, Brasil; lucimari.svp@gmail.com
} 
elabora que la literatura muestra la importancia del uso y del avance de la tecnología de la información para el área del turismo y para la propia preservación de museos.

Palabras claves: Museos; Tecnología de la Información; Turismo

\begin{abstract}
Tourism is characterized by the practice of travel, with leisure purpose, business among others (OMT, 2001). In this context, leisure travel motivated by the cultural tourism segment encompasses several activities of cultural immersion in the destination (BRAZIL, 2010). Museums, as well as cultural tourism elements, are known as places where collections are held and exhibited that reflect some aspect of human existence or its surroundings. With the advancement of society and technologies, the fact of showing information and how to present it has become increasingly relevant. Thus, the visitor no longer wants to be a passive viewer because in a world of ondemand content (on demand) in which he chooses what he wants to see, how and when, how this information is extremely relevant to capture his attention. In this sense, the objective of this study is to make a conceptual approach on the use of digital technologies used for a better dynamics in museums and their educational role. For this, a methodology of exploratory qualitative approach is used, with a technique of bibliographical survey in books and scientific articles found in databases, on the mentioned topic of study. As a result of the study, it is shown that the literature shows the importance of the use and advancement of information technology for tourism and for the preservation of museums.
\end{abstract}

Keywords: Museums; Information Technology; Tourism.

\title{
1. Introdução
}

O turismo, de acordo com a OMT (2001), são as atividades que as pessoas realizam durante suas viagens e estadas em lugares distintos do seu entorno tradicional, que abarquem um período consecutivo menor que 365 dias com a finalidade de lazer, negócios entre outras atividades. Neste sentido visitas ao museu caracterizam atividades de lazer relacionadas ao turismo cultura.

Museus são conhecidos de como lugares onde se guardam e exibem coleções que refletem algum aspecto da existência humana ou seu entorno. Com o avanço da sociedade e das tecnologias o fato de mostrar a informação e como apresentá-la se tornou cada vez mais relevante. O visitante não se limita a ser um espectador passivo, pois num mundo de conteúdo on-demand (sob demanda) em que ele escolhe o que quer ver, como e quando, a forma com que esta informação é extremamente relevante para capturar sua atenção.

Destaca-se ainda a visão de Martins, Baracho e Barbosa (2016, p.6), que os "museus vêm cada vez mais se inserindo em práticas tecnológicas, sejam elas de uso em exposição na divulgação (facebook, blogs, youtube, instragram, etc)", diante desse exposto e da dita globalização há uma "busca por informação rápida e funcional, percebe-se que os museus, como ambientes do conhecimento, estão atentos (uns mais outros menos) a tais situações". 
Neste contexto, surge então a necessidade de um museu que acompanhe a evolução tecnológica da sociedade, com características que o levem a ser participativo, comunicativo e informal, proporcionando um contato mais direto entre o conteúdo e o público. Apresentando conteúdos de forma inovadora, criativa e participativa, antes através de um cartaz agora através de monitores digitais, sistemas de som, projetores de vídeo, projeções imersivas, assistentes virtuais, ou a realidade aumentada sobre as peças expostas sem ter que modificálas, preservando sua segurança e integridade apresentando assim um conteúdo mais interativo.

Tendo em vista essas afirmativas, este estudo visa abordar, o uso de tecnologias digitais empregadas para uma melhor dinâmica em museus e seu papel educativo. Nesse sentido, será feita uma explanação acerca do uso das novas tecnologias e como auxiliam a apreensão do conhecimento. Para tanto, tem como objetivo específico abordar os usos das tecnologias digitais em museus e suas aplicações para empregar dinâmica na experiência de visitação.

\section{Metodologia}

Esta pesquisa classifica se como exploratória que de acordo com (GIL, 1991) visa proporcionar maior familiaridade com o problema com vistas a torná-lo explícito ou a construir hipóteses. Envolve levantamento bibliográfico; análise de exemplos que estimulem a compreensão, referente ao seu procedimento para coleta de dados classifica se como pesquisa bibliográfica a qual de acordo com (GIL, 1991) quando elaborada a partir de material já publicado, constituído principalmente de livros, artigos de periódicos e atualmente com material disponibilizado na Internet. Com a finalidade de formar um referencial sobre museologia, tecnologia, cultura, educação e turismo.

\section{Referencial Teórico}

\subsection{Turismo}

De acordo com Barreto (1991, p. 47) "o Turismo é o fenômeno de interação entre o turista e o núcleo receptor e de todas as atividades decorrentes dessa interação". O turismo ao aliar-se a cultura promove impactos através da valorização de manifestações culturais um desenvolvimento econômico na região significativo. Ao se fazer um paralelo histórico, a relação entre turismo e cultura teve origem no Grand Tour, onde os burgueses viajavam como parte de sua formação para contemplar monumentos, ruínas e obras de arte pelo mundo por meio de longas viagens. 
No que se refere à relação entre turismo e cultura Beni (2000), considera o turismo como um elemento importante da vida social que reflete as verdadeiras pretensões das pessoas no sentido de contemplar novos lugares, compreender, interagir e incorporar novas culturas, descansar e aproveitar das atividades de lazer.

O turismo ao mesmo tempo em que é uma atividade humana diretamente relacionada ao lazer, também é um setor que contribui para a economia, no desenvolvimento cultural, para as práticas esportivas e para a valorização do meio ecológico. Atualmente, o lazer representa as atividades que podem ser desenvolvidas buscando o entretenimento, o descanso e o desenvolvimento pessoal e social (MARCELLINO, 2007).

Para Cazelli, Falcão e Valente (2018, p.68) "ciência, tecnologia e inovação têm sido fatores essenciais no competitivo processo de desenvolvimento de diversas nações", e esses fatores se refletem na área do turismo, onde os museus são um capazes de difundir a cultura por meio, por exemplo, do uso da tecnologia.

\subsection{Museu}

O museu é um elemento de grande importância para o desenvolvimento do turismo cultural, o turismo cultural necessita do museu e às vezes o museu necessita do turismo cultural, é uma questão muitas vezes de sobrevivência, um museu pode viver a margem do turismo e em outros casos não precisar dele (PÉREZ, 2009).

De acordo com Mondo, Silva e Martins (2016, p.894), os “museus não são meramente casas de memórias, e sim espaços que assumem cada vez mais sua função social junto à população como lar para o conhecimento, vivência e transformação".

Chias (2007) coloca que museus precisam possuir um conceito que possa defini-lo, pode ser temático, pode ser resultado de um processo histórico, é necessário que tenha um foco para que se possa definir um público específico, desta forma, poderá se estruturar como um produto turístico.

No que tange à concepção de Lewis $(2014$, p. 1) em relação aos museus, sua proteção e preservação os mesmos:

[...] preservam a propriedade cultural mundial e interpretam-na ao público. Esta não é propriedade comum. Tem um estatuto especial na legislação internacional e normalmente, existe legislação nacional para a proteger. Faz parte do patrimônio natural e cultural mundial e pode ser de caráter tangível ou intangível. Muitas vezes, o bem cultural providencia também a referência primária em vários temas da área, tais como arqueologia e ciências naturais, e por isso representa uma contribuição importante para o conhecimento. É também, um componente significativo na definição da identidade cultural, a nível nacional e internacional. 
Os museus, a cultura e o uso de tecnologias são elementos importantes para o turismo, que podem desenvolver e alavancar a economia, gerando empregos e remanejando divisas por meio da atração de fluxos de visitantes. Tem-se buscado nos dias atuais a promoção da cultura por meio da valorização patrimonial e identitária, além da sustentabilidade participativa, a organização, a conscientização, a profissionalização, visando à eficiência econômica, ao equilíbrio ambiental e à justiça social, (MEDEIROS; MORAES, 2013).

Nesse sentido, o museu é uma ferramenta que contribui para a construção das sociedades e resguardo de sua história, e é uma instituição que serve à sociedade, sendo parte integrante da mesma. Além disso, apresenta os elementos que lhe permitem participar na formação da consciência das comunidades que ele serve, pode contribuir para o engajamento destas comunidades na ação, estabelecendo suas atividades em um conjunto histórico que permite esclarecer os problemas atuais, vinculando o passado ao presente, engajando-se nas mudanças de estrutura em curso e provocando mudanças no interior de suas realidades nacionais (CHILE,1972).

Um elemento importante na relação entre museu e desenvolvimento é o papel educativo que ele tem, para que se possa pensar o turismo cultural como uma experiência de aprendizagem e vivência educativa. Nesta perspectiva, Pérez (2009) traz os três modelos de Valdés Sagues relacionados a museu e educação:

Quadro 1- Modelos de Valdés

\begin{tabular}{|l|l|}
\hline 1 & $\begin{array}{l}\text { Museu e educação formal: O museu serve como instrumento de ensino aprendizagem do } \\
\text { curriculum escolar. Serve para reforçar o conhecimento através de unidades didácticas para alunos } \\
\text { e docentes. Tenta criar hábitos de consumo cultural entre os escolares. Ex.: Visitas programadas } \\
\text { pelos professores. }\end{array}$ \\
\hline 2 & $\begin{array}{l}\text { Museu e educação não formal: O museu é um instrumento de difusão de conhecimento gerado por } \\
\text { ele ou por investigadores, que completa e complementa a educação formal escolar. As actividades } \\
\text { são destinadas a públicos alvo mais genéricos que utilizam os seus tempos de lazer nestas } \\
\text { actividades. Ex.: palestras, cursos, ateliers, visitas guiadas... }\end{array}$ \\
\hline 3 & $\begin{array}{l}\text { Museu e educação informal: o museu é entendido como um meio de comunicação que elabora } \\
\text { exposições dialógicas para relacionar visitantes, obras e museu. O museu propicia assim } \\
\text { divulgação científica, mas também mediação e interpretação de significados entre os visitantes e a } \\
\text { instituição museal. O visitante dispõe-se a ser um participante activo, voluntário, que assume uma } \\
\text { educação não integrada nos currículos escolares oficiais. }\end{array}$ \\
\hline
\end{tabular}

Fonte: Pérez, 2009, adaptado pelos autores. 
Ao se acreditar na atividade do turismo enquanto processo educativo aos sujeitos que constituem essa atividade e, portanto, à comunidade que acolhe seus visitantes, considera-se que o museu em evidência abre espaço às práticas de cunho educativo-ambiental, porque possibilita atividades capazes de reforçar o sentido de pertencimento e a problematização acerca do conceito de sustentabilidade a partir do resguardo das memórias e história ambiental local.

Dessa maneira, cabe registrar que considera-se o turismo, em seu caráter educativo, quando articulado ao envolvimento com a comunidade que busca a disseminação de sua história, mas uma história que considere o par homem/natureza de maneira relacional, sem dicotomias e com o compromisso da memória social como registra acima Carvalho (2004).

\subsection{Uso de tecnologia em espaços museais}

As seções devem ser numeradas com números arábicos a partir do 1 (um) e ter o título alinhado à esquerda. Já as subseções devem seguir a numeração progressiva a partir da seção primária e também devem estar alinhadas à esquerda e em negrito.

A etimologia da palavra tecnologia provém do latim techné, e faz referência a um "conjunto de conhecimentos, especialmente princípios científicos, que se aplicam a um determinado ramo de atividade" (FERREIRA, 1993, p. 528). Considerando isso, se percebe que o ser humano vive no constante processo de criar invenções, como ocorreu na revolução industrial, quando surgiram, por exemplo, as máquinas impressas permitindo que notícias e livros tivessem a possibilidade de alcance mundial. Outros momentos relevantes são o surgimento da televisão, do cinema, do rádio e da internet.

Para Gouvêa e Leal (2000, p.69), “o fato concreto é que os impactos da tecnologia têm implicações sociais tanto nas relações sociais macro (macro-sistemas de transporte, em formação, energia, alimentação etc.) quanto na intimidade da vida técnica cotidiana".

Desta forma compreende-se que, a tecnologia pode permitir que o museu seja mais acessível à comunidade em contraposição a concepção da preservação prioritária dos bens culturais de uma elite. Se a comunidade é excluída da atividade de preservação do patrimônio, esta causara um distanciamento entre ela e o museu. $\mathrm{O}$ foco dos museus deve estar na experiência do visitante e no aprendizado que ele terá nesta atividade (GONÇALVES, 2005).

O Conselho Internacional de Museus - ICOM define como museu, "toda instituição permanente, sem fins lucrativos, aberta ao público, que adquire, conserva, pesquisa e expõe coleções de objetos de caráter cultural ou científico para fins de estudo, educação e 
entretenimento". Estes fins contribuem para considerar o museu como um atrativo turístico, o qual deve estar em constante desenvolvimento para adaptar-se a demanda dos visitantes, que evoluem com o avanço da tecnologia e necessitam de que estes atrativos se adaptem ao seu novo estilo de vida e a suas novas necessidades, as quais pedem dinâmicas de apresentação que se adapte ao contexto atual. Além de facilitar o acesso a informação em uma atividade de lazer.

A presença digital em instituições museológicas já é uma realidade. Alguns museus contam com seu acervo digitalizado e disponibilizam na grande rede mundial de computadores a internet. Dentre esses acervos podem ser encontrados livros, textos, imagens e vídeos, simulações digitais de objetos e cenários em três dimensões (OLIVEIRA et al., 2014)

O uso de tecnologias da informação em um museu agrega valor ao material, e torna-se um recurso relevante para pesquisas, já que possibilita ao usuário poder construir seu próprio caminho interpretativo e seu próprio roteiro sem prejuízo de áreas físicas de exposição e guarda dos diversos acervos. Um aspecto interessante da digitalização de acervos é possibilita o acesso ao público a informações digitais de arquivos ou objetos que muitas vezes o museu por limitações de espaço físico, deixa parte de seus objetos arquivados como cadastro de reserva.

O uso da inteligência artificial, através de assistentes pessoais que podem interpretar perguntas do visitante e com base no seu banco de dados dar uma resposta mais precisa e interativa. Além de permitir, por exemplo, fazer uso virtualmente de um personagem histórico. Tours virtuais explorando um cenário recriado em detalhes, onde o visitante pode interagir com os objetos. São propostas que podem tanto ser levadas ao visitante tanto através da internet como no próprio espaço físico do museu.

Ao se referir especificamente ao espaço físico do museu, o uso de realidade aumentada (tecnologia que utiliza um marcador, webcam ou de um smartphone, ou para a inserção de objetos virtuais no ambiente físico) misturando espaços físicos e virtuais, onde aplicativos de smartphones podem reconhecer objetos na exposição e dar outras informações, como sua contextualização, ou dar orientações no tour através de uma inteligência artificial, como é possível hoje através do Watson (plataforma de computação cognitiva da empresa de tecnologia IBM). A imersão através de óculos de realidade virtual que permitem que o usuário se transporte para outro lugar no tempo e espaço. A possibilidade do material se adaptar a língua das pessoas, pois não depende do conhecimento do guia para explicação em outro idioma. Projeção de sons para ambientação, réplicas de objetos produzidos em 
impressoras 3D, até a possibilidade de esconder pistas nos objetos expostos ou incentivos a interação com todo o acervo através recompensas.

Designamos importante apontar o papel educativo do museu e o uso da tecnologia no mesmo, tendo em vista que ao se estimular o ser social em relação à preservação do patrimônio utilizando recursos tecnológicos é possível ter um cidadão consciente. O que é de extrema importância tendo em vista que os museus possuem inúmeras funções de aquisição e preservação de coleções, onde "procuram fazer uso dos aspectos tangíveis e intangíveis da herança cultural que ajudam a compreender, explicar e vivenciar as circunstâncias sociais, económicas e históricas que moldaram as diversas comunidades" (NABAIS, 1985, p. 211).

\section{Conclusões}

O tema proposto neste artigo abordou algumas possibilidades de relações existentes entre o museu e a tecnologia. Assim, apresentou seus conceitos e possibilidades acerca do auxílio que as novas tecnologias podem trazer para este. A partir dos exemplos apresentados, pensar no museu como opção de lazer dentro do turismo se torna mais viável, considerando a interação com as novas tecnologias para que o seu desenvolvimento que enriquece a experiência da visita, permitindo ao espectador interagir com o conteúdo que lhe é apresentado, despertando assim, o desejo por aprender, diferente de quando as informações eram exibidas através de vitrines para um espectador passivo.

Estas tecnologias facilitam uma maior interação tornado o museu mais acessível e atrativo, como uma apresentação lúdica para crianças. E que pode proporcionar a inclusão de pessoas surdas e deficientes auditivos que requerem o conhecimento da linguagem de libras do guia, ou o emprego de texto e vídeos autoexplicativos. Oferece a oportunidade para pessoas cegas ou com baixa percepção visual através de sensores de presença e audiodescrição que trazem informações do objeto exposto, além de descrever imagens. Cabe salientar que é necessário ter cuidado para que o uso não distraia os visitantes, mas que ela complemente essa experiência de ensino.

Denota-se que este é apenas um trabalho de reflexão teórica, e que é necessário mais avanços nos estudos relacionados à tecnologia nos espaços museais, desta forma encoraja-se outros pesquisadores a avançar desta pesquisa utilizando a teoria para leitura da realidade e realizando estudos aplicados.

\section{Referências}


BARRETTO, Margarita. Planejamento e organização em turismo. Campinas: Papirus,1991.

BENI, C. M. Política e estratégia regional: Planejamento integrado e sustentável do turismo. In:LAGE, B. H. G.; MILONE, P. C. (Orgs.) Turismo: Teoria e Prática. São Paulo: Atlas, 2000. p. 168.

BRASIL, Ministério do Turismo. Segmentação do turismo e o mercado. Secretaria Nacional de Políticas de Turismo, Departamento de Estruturação, Articulação e Ordenamento Turístico, Coordenação Geral de Segmentação. - Brasília: Ministério do Turismo, 2010

CARVALHO, Ely Bergo de. A História Ambiental e a "crise ambiental" contemporânea: um desafio político para o historiador. Revista Esboços, Florianópolis, v. 11, n. 11, p.1-12, nov. 2004.

CAZELLI, Sibele; FALCÃO, Douglas; VALENTE, Maria Esther. Visita estimulada e empoderamento: por um museu menos excludente. Caderno Virtual do Turismo, v. 18, n. 1, 2018.

CHIAS, Josep. Turismo o Negócio da Felicidade: Desenvolvimento e marketing turístico de países, regiões e cidades. São Paulo: Senac, 2007.

CHILE, Santiago del. Mesa Redonda sobre a importância e desenvolvimento dos Museus no mundo contemporâneo. 1972. Disponível em: <http://www.ibermuseus.org/wpcontent/uploads/2014/09/Publicacion_Mesa_Redonda_VOL_I.pdf $>$. Acesso em: $10 \mathrm{fev}$. 2015 .

FERREIRA, Aurélio Buarque de Holanda. Minidicionário da língua portuguesa. 3.ed. Riode Janeiro: Nova Fronteira, 1993.

GIL, Antonio Carlos. Como elaborar projetos de pesquisa. São Paulo: Atlas, 1991.

GONÇALVES, José Reginaldo. Os museus e a representação do Brasil: os museus como espaços materiais de representação social. In: CHAGAS, Mario (org.). Museus: antropofagia da memória e do patrimônio. Revista do Patrimônio Histórico e Artístico Nacional. Brasília, no. 31 , p.254-273, 2005

GOUVEA, Guaracira; LEAL, Maria Cristina. Uma visão comparada do ensino em ciência, tecnologia e sociedade na escola e em um museu de ciência. Ciênc. educ. (Bauru), Bauru, v. $7, \quad$ n. 1 , p. 67-84, 2001.20 Disponivel em <http://www.scielo.br/scielo.php?script=sci_arttext\&pid=S1516-

73132001000100005\&lng=en\&nrm=iso>. Acesso em $09 \quad$ Jan. 2019. http://dx.doi.org/10.1590/S1516-73132001000100005.

LEWIS, Geoffrey. O Papel dos Museus e o Código de Ética Profissional. In: BOYLAN, Patrick J. (Ed.). Como Gerir um Museu: Manual Prático. Paris: Franly S.a., 2014. p. 1-252.

MARCELLINO, Nelson Carvalho et al. Lazer, cultura e patrimônio ambiental urbano: políticas públicas: o caso de Campinas e Piracicaba- SP. Curitiba: OPUS, 2007. 177 p. 
MARTINS, Cesar Eugenio M. A.; BARACHO, Renata Maria Abranches; BARBOSA, Cátia Rodrigues. OS MUSEUS NA ERA DA INFORMAÇÃO: análise do uso de recursos tecnológicos. Colóquio Ibero-americano Paisagem Cultural, Patrimônio e Projeto. UFMG, Belo Horizonte-MG, 2016.

MEDEIROS, Lindenberg da Câmara; MORAES, Paulo Eduardo Sobreira. TURISMO E SUSTENTABILIDADE AMBIENTAL: REFERENCIAS PARA O DESENVOLVIMENTO DE UM TURISMO SUSTENTÁVEL. Revista Meio Ambiente $e$ Sustentabilidade, Curituba, v. 2, n. 3, p.197-234, 2013. Semestral.

MONDO, Tiago Savi; SILVA, Francine Vieira Correa da; MARTINS, Ana Iwaki. Qualidade De Serviços Em Museus: A Percepção Dos Visitantes Do Museu Histórico De Santa Catarina / Services Quality In Museums: The Perception Of Visitors Of Santa Catarina Historical Museum. Revista Eletrônica de Administração e Turismo, v. 8, n. 4, p. 890-909, 2016.

NABAIS, A. The development of ecomuseums in Portugal. Museum, (148), 211-216. Oppenheimer, F. (1975). The exploratorium and other ways of teaching physics. Physics Today, 28 (9), 9-13, 1985.

OLIVEIRA, BERNARDO JEFFERSON; CAMPOS, VERONA; REIS DEBORA D'AVILA; LOMMEZ, RENE. O fetiche da interatividade em dispositivos museais: eficácia ou frustração na difusão do conhecimento científico. Revista Museologia $e$ Patrimônio, v.7, n.1, 2014. <http://revistamuseologiaepatrimonio.mast.br/index.php/ppgpmus/article/view/273/267>. Acesso em: 15 nov. 2017.

OMT. Organização Mundial do Turismo. Introdução ao turismo. Tradução de Dolores Martin Rodriguez Córner. São Paulo: Roca, 2001.

PÉREZ, Xerardo Pereiro. Turismo Cultural: Uma Visão Antropológica. 2. ed. Tenerife (españa): Pasos, 2009.

SANTOS, G. M. D. Museu Municipal Coronel Tancredo Fernandes, 2011. Disponivel em: <http://museutancredomellosvp.webnode.com.br/historia/>. Acesso em: 12 nov. 2015.

SWARBROOKE, John. Turismo Sustentável: Conceitos e Impacto Ambiental. Volume 1, $3^{\mathrm{a}}$ edição, São Paulo: Editora Aleph, 2002. 